\title{
O Banco Central no Governo Lula
}

Fernando de Holanda Barbosa*

RESUMO - Este artigo faz uma avaliação do BACEN no Governo Lula, analisando quatro temas: i) execução da política monetária, ii) formulação e execução da política de reservas internacionais, iii) execução da política de emprestador de última instância do sistema financeiro e iv) regulamentação e supervisão do sistema financeiro.

Palavras-chave: Metas de inflação. Reservas internacionais. Emprestador de última instância. Regulação do sistema financeiro.

\section{INTRODUÇÃO}

O Banco Central do Brasil (BACEN), de acordo com a Lei 4595, de 31/12/1964, e legislação subsequente aprovada pelo Congresso Nacional, tem as seguintes atribuições: i) executa a política monetária; ii) formula e executa a política de reservas internacionais, bem como administra as mesmas; iii) empresta, em última instância, recursos para o sistema financeiro quando ocorre uma crise de liquidez; iv) regulamenta e supervisiona o sistema financeiro; v) administra e supervisiona o sistema de pagamentos e recebimentos da economia; e vi) funciona como banco do governo. Este artigo tem como objetivo fazer uma avaliação do BACEN no Governo Lula, analisando as quatro primeiras atribuições porque as duas últimas são tarefas rotineiras que o banco central executa com eficiência.

\section{POLÍTICA MONETÁRIA}

A formulação da política monetária compete ao Conselho Monetário Nacional (CMN), que desde 1999 estabelece as metas de inflação. O CMN tem como membros o Presidente do Banco Central e os Ministros do Planejamento e da Fazenda, sendo esse último o Presidente do Conselho. O BACEN desde o Plano Real tem tido liberdade operacional na execução da política monetária. No Governo Lula, além dessa liberdade operacional, o Presidente Henrique Meirelles possivelmente negociou e obteve, quando aceitou o cargo, o sistema que no meio político é conhecido como "porteira fechada", isto é, a liberdade de escolher, sem interferência política, toda a diretoria do BACEN.

O BACEN em 2003 não foi capaz de cumprir a meta de inflação fixada pelo CMN, em virtude do efeito Lula. A vitória do candidato do PT na eleição de 2002 foi interpretada por boa

* Doutor em economia pela Universidade de Chicago. É professor titular da Universidade Federal Fluminense e da Fundação Getúlio Vargas. Endereço eletrônico: fernando.holanda@fgv.br. 
parte da sociedade brasileira como sinal de que o calote da dívida pública era uma possibilidade não desprezível. A fuga de capital fez com que a taxa de câmbio tivesse um aumento substancial. Este aumento foi repassado parcialmente para os preços dos bens e serviços. Boa parte da população também acreditava que o BACEN de Lula não usaria a taxa de juros para conter a inflação. A taxa esperada da inflação aumentou e a mesma ameaçava ir para um novo patamar.

TABELA 1 - METAS DE INFLAÇÃO (\%)

\begin{tabular}{lr|r|r|r|r|r|r|r}
\hline \multicolumn{1}{c|}{ ANO } & \multicolumn{1}{c}{$\mathbf{2 0 0 3}$} & \multicolumn{1}{c}{$\mathbf{2 0 0 4}$} & \multicolumn{1}{c}{$\mathbf{2 0 0 5}$} & \multicolumn{1}{c}{$\mathbf{2 0 0 6}$} & \multicolumn{1}{c}{$\mathbf{2 0 0 7}$} & \multicolumn{1}{c}{$\mathbf{2 0 0 8}$} & \multicolumn{1}{c}{$\mathbf{2 0 0 9}$} & $\mathbf{2 0 1 0}$ \\
\hline META & $4,0 \pm 2,5$ & $5,5 \pm 2,5$ & $4,5 \pm 2,5$ & $4,5 \pm 2,0$ & $4,5 \pm 2,0$ & $4,5 \pm 2,0$ & $4,5 \pm 2,0$ & $4,5 \pm 2,0$ \\
INFLAÇÃO & 9,30 & 7,60 & 5,70 & 3,14 & 3,14 & 5,90 & 4,31 & $5,80^{*}$ \\
\hline
\end{tabular}

NOTA: *Previsão em 12/2010.

O primeiro ano do Governo Lula teve que lidar com este problema aumentando tanto a taxa de juros como o superávit primário. Como mostra a Tabela 1, o BACEN, a partir de 2004 cumpriu integralmente as metas de inflação estabelecidas pelo CMN. Em 2006, 2007 e 2009 a inflação ficou abaixo ou praticamente no centro da banda. Nos demais anos, a taxa de inflação ficou um pouco acima do centro da banda.

A crítica de que o BACEN errou na mão, aumentando demasiadamente a taxa de juros, não procede. Se esse fosse o caso, teríamos sistematicamente a taxa de inflação abaixo do centro da meta. Tal fato não ocorreu. Na verdade, os dados sugerem o contrário: nos oito anos do Governo Lula, a taxa de inflação ficou acima do centro da meta em cinco anos.

GRÁFICO 1 - INFLAÇÃO (IPCA) X SELIC

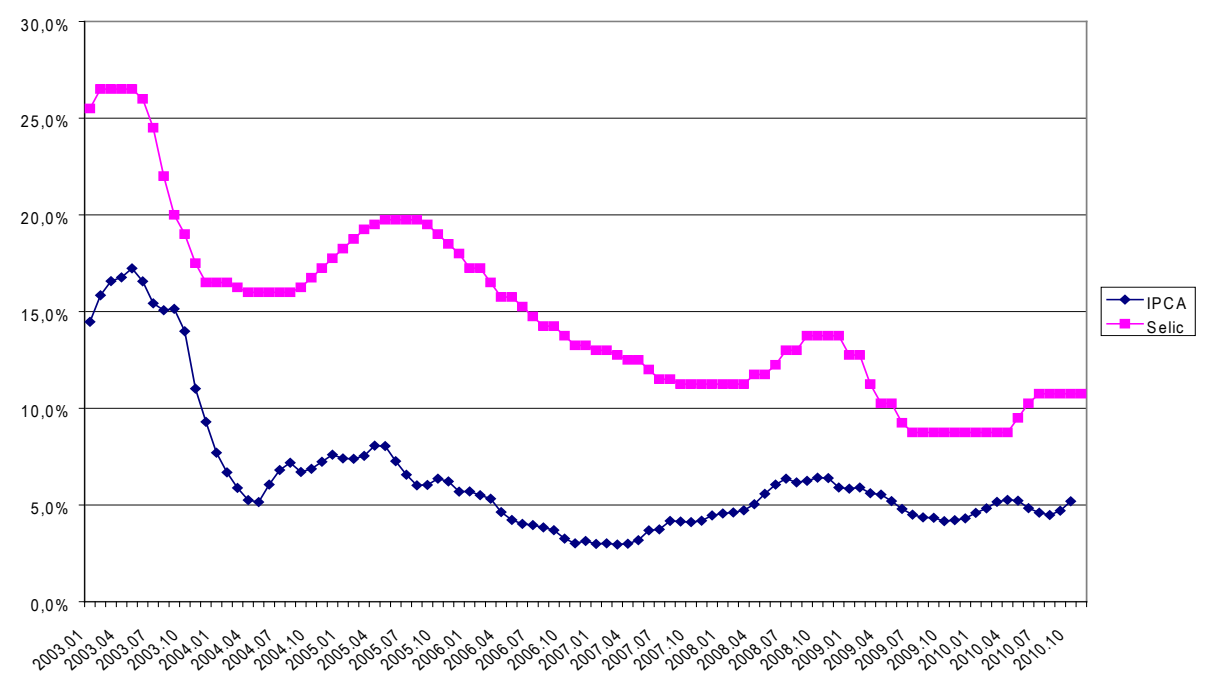

O Gráfico 1 mostra a evolução da taxa de juros SELIC no período de janeiro de 2003 até dezembro de 2010. Essa figura nos permite dividir a política monetária no Governo Lula em quatro ciclos. O primeiro começa em janeiro de 2003 e vai até abril de 2004 . O pico da taxa 
é de 26,5\% ao ano, começando a ser reduzida em junho de 2003, quando o COPOM a fixou em $26 \%$, uma redução de 50 pontos (0,5\%). A taxa de juros de $16 \%$ ao ano é a mais baixa desse período, que terminou em abril de 2004 quando a taxa subiu para 16,25\%. O segundo ciclo é o mais longo. Ele teve início em novembro de 2004 e terminou em abril de 2008. A taxa de juros no pico foi igual a 19,75\% ao ano. Em setembro de 2005 foi reduzida em 25 pontos básicos. O vale foi igual a 11,25\%. Em abril de 2008 iniciou-se um novo ciclo, quando o COPOM aumentou a taxa SELIC para $11,75 \%$. O término desse período ocorreu em março de 2010, quando a taxa era igual a $8,75 \%$ ao ano. A taxa de juros no pico foi igual a 13,75\% ao ano. Em janeiro de 2009 o COPOM a reduziu em 100 pontos, estabelecendo a mesma em 12,75\%. O fim do terceiro ciclo e começo do quarto ocorreu em março de 2010, quando a SELIC aumentou de $8,75 \%$ para $9,50 \%$ ao ano. A taxa de juros em dezembro de 2010 , igual a $10,75 \%$, certamente aumentará nos próximos meses. Portanto, esse último período ainda está inacabado e terá sua continuação no Governo Dilma. Esses ciclos indicam que o BACEN não conseguiu fazer uma sintonia fina para uma aterrissagem suave, tendo que arremeter o avião (os juros) toda vez que tentava aterrissar (que chegava ao vale).

Outra característica desses ciclos é de que as taxas de juros, tanto no pico como no vale, têm sido cada vez menores. Esse fato corresponde a uma redução da taxa de juros natural da economia, que era extremamente elevada no início do Governo Lula, e que foi caindo ao longo do seu governo. Essa redução está associada à queda da taxa de juros dos títulos da dívida pública brasileira, que diminuiu por duas razões. A primeira foi a decisão do Presidente Lula de honrar os contratos e pagar a dívida. Como conseqüência, o risco Brasil caiu substancialmente, mantendo-se num patamar baixo ao longo do tempo. A segunda razão para a queda na taxa de juros da dívida pública brasileira foi o excesso de liquidez mundial.

A taxa SELIC é contaminada pela da dívida pública brasileira devido à existência de títulos, as Letras Financeiras do Tesouro (LFT's), indexados a taxa do BACEN. A arbitragem nos mercados financeiros implica que a taxa de juros no mercado interbancário de reservas, a taxa SELIC, seja igual à taxa de juros dos títulos públicos. Esta é a jabuticaba brasileira que produz uma excrescência: a liquidez no Brasil é remunerada pela mesma taxa de juros dos títulos de longo prazo. O BACEN no período Lula ignorou esse fato e não tomou nenhuma decisão para acabar com essa situação esdrúxula. Resultado: o Brasil continua sendo campeão na competição de juros, de curto prazo, entre bancos centrais do mundo.

\section{RESERVAS INTERNACIONAIS}

O BACEN tomou a decisão, a partir de 2006, de mudar a política de reservas inter- 
nacionais e começou a acumular reservas, como indica o Gráfico 2. Num regime de câmbio flexível puro, os bancos centrais não intervêm no câmbio, deixando que o preço da divisa seja determinado pelo mercado. Na prática, o regime de câmbio flexível é "sujo", isto é, os bancos centrais intervêm no câmbio. Quais as razões que fundamentam tal comportamento? Em primeiro lugar, se deixar que o mercado funcione sem intervenção, ele pode ser bastante volátil. O banco central atua para reduzir a volatilidade do mercado. Em segundo lugar, o mercado de câmbio é um mercado de ativo e como tal podem existir bolhas. Cabe ao banco central intervir toda vez que acredite que exista uma bolha. A terceira razão para que o banco central acumule reservas é a possibilidade de uma crise financeira internacional interromper o fluxo de crédito para o país, exigindo uma mudança abrupta e de magnitude não desprezível na taxa de câmbio.

A acumulação de reservas implica num custo para o país. A esterilização das reservas requer o financiamento das mesmas pela taxa de juros SELIC e sua aplicação nos mercados financeiros internacionais rende uma taxa de juros próxima de zero porque elas são aplicadas em títulos de curto prazo. Aqueles que defendem essa política argumentam que as reservas funcionam como um seguro e que o custo de seu carregamento é equivalente ao prêmio de seguro. Todavia, qualquer cálculo mostra que o preço desse seguro é exorbitante. Argumentam também que a crise financeira de 2008 demonstrou que as reservas internacionais foram essenciais para tornar o tsunami numa marola. Os números não suportam esse argumento porque apenas uma fração das reservas foi usada naquela ocasião.

GRÁFICO 2 - CÂMBIO NOMINAL E RESERVAS

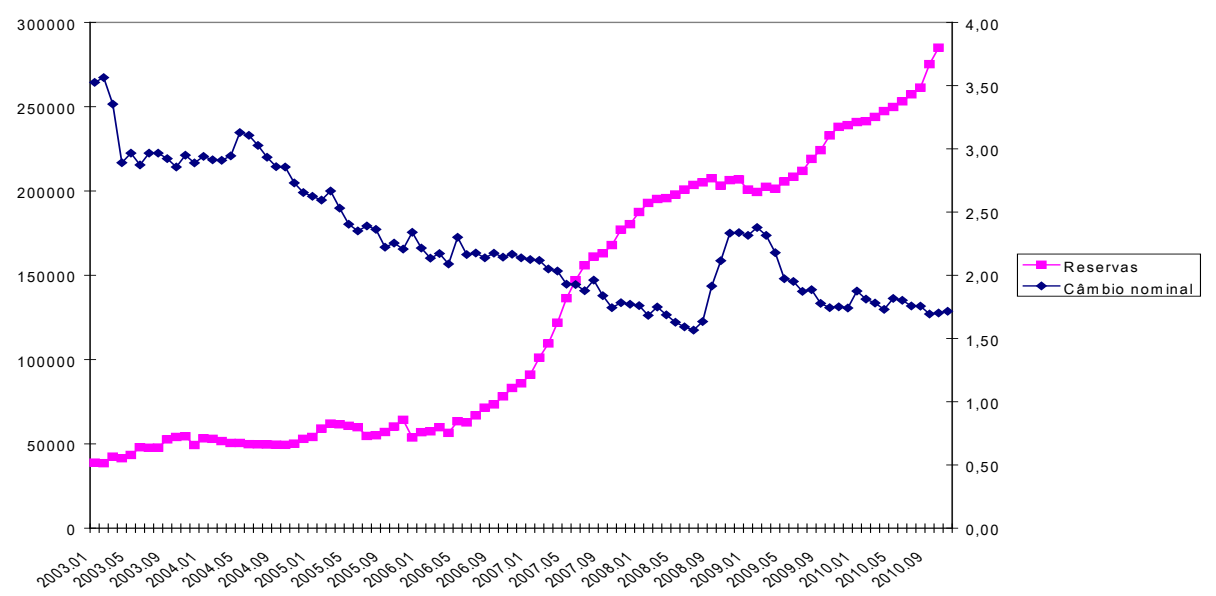

O Gráfico 2 mostra a verdadeira razão para o acúmulo de tantas reservas no Brasil a partir de 2006: a taxa de câmbio caminha ladeira abaixo, exceto no auge da crise, enquanto as reservas internacionais sobem a ladeira. O discurso oficial do BACEN era de que o mesmo 
não interferia na tendência do mercado. A prática, como pôde ser visto no referido gráfico, era de que a política de acumulação de reservas tinha como objetivo impedir a apreciação do real. Até que ponto o BACEN impediu uma apreciação bem maior do que aquela que ocorreu? Essa pergunta é difícil de ser respondida. Todavia, cabe outra pergunta: se é para intervir no câmbio para não apreciá-lo porque não fazê-lo por outros caminhos, inclusive usando a política fiscal?

\section{AGÊNCIA REGULADORA DO SISTEMA FINANCEIRO}

O BACEN é a agência reguladora do sistema financeiro. Em outros países, o arranjo institucional é diferente do brasileiro. Por exemplo, na Europa do euro o Banco Central não é responsável pela regulação do sistema financeiro. A primeira pergunta que cabe fazer é a seguinte: por que regular o sistema financeiro? A teoria econômica nas últimas décadas avançou bastante na economia da informação, estudando os problemas suscitados pela informação assimétrica: o marido traído (o cliente do banco) é o último a saber. O banco sabe o que está fazendo com seu dinheiro, porém você, o cliente, nem sempre dispõe da informação. O banco central tem que criar regras e procedimentos que desencorajem práticas lesivas ao interesse social. Ademais, no setor bancário a entrada de novas empresas não é livre, precisando de autorização do banco central. A existência de barreira à entrada neste setor pode fazer com que várias instituições tenham poder de mercado e usem esse poder para cobrar tarifas e preços abusivos.

No governo Lula ocorreram várias fusões e aquisições no setor bancário que aumentaram a concentração no mesmo. As mais conhecidas foram a compra da Nossa Caixa pelo Banco do Brasil, a compra do Banco Real pelo Banco Santander e a fusão do Unibanco com o Itaú. A despeito dessa concentração bancária, a atuação do BACEN, enquanto agência reguladora, deixou a desejar: os serviços bancários são caros e o spread bancário continua imbatível. Possivelmente somos campeões mundiais nessa modalidade.

\section{EMPRESTADOR DE ÚLTIMA INSTÂNCIA}

Os bancos centrais exercem uma função crucial em qualquer crise financeira: eles são os emprestadores de última instância, impedindo que uma instituição ilíquida se transforme em insolvente e contamine as demais instituições do sistema. A crise financeira desencadeada nos EUA em 2008, pelo mercado de hipotecas de alto risco (denominado em inglês de subprime) mostrou que essa função tem um escopo muito mais amplo do que tinha no passado, exigindo que instituições quase-financeiras também recebam socorro do banco central. Caso contrário, uma grande recessão poderia ter se transformado numa depressão. 
Aqui no Brasil, um grupo de bancos, de pequeno e médio porte, teve dificuldade em manter suas linhas de crédito externo para financiar suas operações. Caso o BACEN deixasse esses bancos entregues à própria sorte eles teriam que vender seus ativos na bacia das almas. Tal fato não ocorreu porque o BACEN criou mecanismos de liquidez que evitaram o problema no nascedouro, não permitindo que a crise no mercado de crédito internacional em 2008 se propagasse para o Brasil.

\section{CONCLUSÃO}

As conclusões desse artigo sobre o Banco Central no Governo Lula são as seguintes: i) o BACEN teve um excelente desempenho no controle da inflação, cumprindo rigorosamente as metas fixadas pelo $\mathrm{CMN}$; ii) a política de reservas internacionais produziu uma acumulação de reservas exagerada, não justificável para um país que tem sistema de câmbio flexível, com um custo social incompatível com a pobreza do país; iii) o BACEN não desempenhou a contento suas funções de agente regulador do sistema financeiro e deveria criar uma diretoria que fosse responsável por tal função; iv) o BACEN exerceu seu papel de emprestador de última instância, criando a liquidez necessária para que a crise do mercado de crédito internacional de 2008 não se propagasse em nosso país. 